\title{
PSA Level
}

National Cancer Institute

\section{Source}

National Cancer Institute. PSA Level. NCI Thesaurus. Code C124827.

The concentration of prostate specific antigen in a sample. 